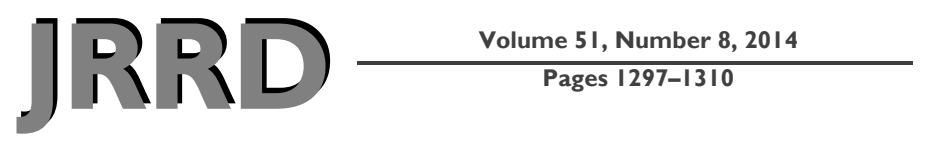

\title{
Computer simulations of efficacy of air-cell-based cushions in protecting against reoccurrence of pressure ulcers
}

\author{
Ayelet Levy, MSc; ${ }^{1}$ Kara Kopplin, BS; ${ }^{2}$ Amit Gefen, PhD $^{\mathbf{1}^{*}}$ \\ ${ }^{1}$ Department of Biomedical Engineering, Faculty of Engineering, Tel Aviv University, Israel; ${ }^{2}$ Efficacy Research, Stan- \\ dards and Public Policy, ROHO Inc, Belleville, IL
}

\begin{abstract}
For individuals with a spinal cord injury (SCI) who depend on a wheelchair for mobility, sitting-acquired pressure ulcers (PUs) are a common and life-endangering complication. In the short time following an SCI, pathoanatomical and pathophysiological changes that affect the weight-bearing tissues of the buttocks may increase the risk for PUs, exposing this already-at-risk population to the additional potential risk caused by soft tissue scarring. In this work, we evaluated the biomechanical efficacies of an air-cell-based (ACB) cushion for individuals with SCI who have previously experienced PUs that healed but left scars in their soft tissues. We used 11 finite element model variants of the buttocks describing various scar shapes and severities to study the effects of the scars on soft tissue stresses during sitting on an ACB cushion and the resulting theoretical risk for the reoccurrence of PUs. Interestingly, the ACB cushion induced, in general, lower peak stress values in the soft tissues of the buttocks when scarring was present with respect to the stress levels in the (nonscarred) reference case. Our simulations therefore suggest that the ACB cushion is generally better at protecting patients with a history of severe PUs manifested by large, possibly deep tissue scarring in their buttocks.
\end{abstract}

Key words: deep tissue injury, finite element modeling, pressure ulcer, risk factors, scars, sitting biomechanics, spinal cord injury, support surfaces, wheelchair, wheelchair cushion.

\section{INTRODUCTION}

Pressure ulcers (PUs) are localized injuries to the skin and/or underlying tissues that develop as a result of excessive and sustained pressure and/or shear, usually under a weight-bearing bony prominence [1]. While superficial (skin) PUs are more commonly associated with shear loads, moisture/wetness, and other microclimate factors [2], deeper tissues, particularly muscles, are more susceptible to direct deformation damage known as deep tissue injury (DTI) $[1,3]$. Individuals with a spinal cord injury (SCI) who depend on a wheelchair for mobility are at a greater risk for developing sitting-acquired PUs and specifically DTIs, commonly under their ischial tuberosities (ITs) [3-6].

The incidence of PUs is estimated to be between onequarter and one-third of the SCI population in community settings in the United States and Europe [7-8] and remains an important secondary complication to SCI and the second most common reason for rehospitalization [9]. PUs are associated with increased morbidity and mortality as well as reduced quality of life for both the individuals with SCI and their caregivers [10-11]. An additional burden is laid on the healthcare system, e.g., the total average

Abbreviations: $3 \mathrm{D}=$ three-dimensional, $\mathrm{ACB}=$ air-cellbased, BW = body weight, DTI = deep tissue injury, FE = finite element, HG = hourglass-shaped scarring, IT = ischial tuberosity, $\mathrm{MRI}=$ magnetic resonance imaging, $\mathrm{PU}=$ pressure ulcer, $\mathrm{R}=$ reference, $\mathrm{SCI}=$ spinal cord injury, $\mathrm{SW}=$ sandwich-shaped scarring, Thin $=$ thin skin scar.

*Address all correspondence to Amit Gefen, PhD; Department of Biomedical Engineering, Faculty of Engineering, Tel Aviv University, Tel Aviv 69978, Israel; +972-36408093; fax: +972-3-6405845. Email: gefen@eng.tau.ac.il http://dx.doi.org/10.1682/JRRD.2014.02.0048 
monthly cost per community-dwelling individuals with SCI and PUs in the Canadian system was $\$ 4,300$ U.S. [12]. The development of a single full-thickness PU in U.S. hospitals can increase hospital charges by $\$ 2,000$ $\$ 11,000$ U.S. and lengths of stay fivefold $[10,13]$.

In patients with impaired mobility and/or sensation, sustained local mechanical strains and stresses in the soft tissues of the buttocks are known to impose a threat to tissue viability and integrity through direct mechanical damage to the deformed cells and tissues [3,14-17], which is then potentially superimposed with ischemic and reperfusion damage [15-16,18-19]. Extensive efforts are invested in understanding the etiology, and indeed, substantial progress was made in the last decade as detailed in the aforementioned articles. This new knowledge should now allow for more efficient risk assessment and revised prevention strategies, targeting populationspecific risk factors [20-22]. In light of this knowledge that local excessive deformations of soft tissues may jeopardize tissue viability, the most important guideline for preventing sitting-acquired PUs is to use a soft and thick-enough cushion on the wheelchair [1]. Cushions are generally aimed at better distributing the buttocks-support contact as well as the internal tissue loads, which in the context of DTI prevention means that strains and stresses in the glueal muscle regions overlying the ITs should be as low as possible $[1,3]$.

In the months and years following an SCI, several profound anatomical and physiological changes take place in the buttocks as the weight-bearing tissues adapt to the chronic sitting and disuse [23]. These phenomena include considerable weight gain, muscular atrophy, spasms and intramuscular fat infiltration, flattening of the ITs, and changes in skin structure and mechanical properties, to name a few [23]. All of these, together, change the structure and hence the load-bearing function of the buttocks, which then affects the internal tissue loading state during sitting [23]. Many of the structure-function changes in the buttocks that are characteristic to the SCI population may theoretically elevate the risk for sittingacquired PUs [24-28]. Indeed, PUs are more prevalent in individuals with an SCI, leaving this already-at-risk population with the additional potential risk of soft tissue scarring as a result of a PU. As scars become mechanically stiffer lesions because of the less organized collagen network and interlinking [29], they may increase the risk of a recurrent DTI by generating stress concentrations within and around them. Epidemiological data support this hypothesis, considering substantially high rates of
PU reoccurrence among individuals with a SCI, ranging from 31 to 79 percent, have been reported [30].

Finite element (FE) modeling has been employed in the past, both for examining potential risk factors for PU development and for evaluating the biomechanical efficacies of support surfaces. It is an efficient research methodology because it allows isolating population-specific or cushion-specific characteristics that are extremely difficult to investigate by means of randomized controlled trials [31-32]. Several studies have recently used FE modeling to explore how the previously described SCIrelated changes affect the internal loading state in the soft tissues of the buttocks during sitting [20-22,33-35]. These studies investigated the contribution of variations in body mass index, muscle atrophy and spasms, intramuscular fat infiltration, IT flattening, and tissue scarring; however, they all used standard flat foam cushions as supports. Additionally, many studies employed FE modeling to evaluate the biomechanical efficacies of wheelchair cushions [20,34-41], but all have simulated homogeneous foam cushions (with different material behaviors and stiffnesses). Recently, we were able to computationally evaluate, for the first time, the biomechanical performances of a much more sophisticated aircell-based (ACB) cushion structure [42] and have used it to study muscle, fat, and skin stresses during sitting when SCI-related disuse adaptations to the buttocks were present.

The focus of the present study was to evaluate the biomechanical performances of the ACB cushion for patients who are at a potentially increased risk for PUs, that is, ones who have previously experienced deep or superficial PUs that healed but left scars in the soft tissues of the buttocks. We used 11 model variants describing various scar shapes and severities, in comparison to a reference (R) nonscarred case, to study the effects of the scars on soft tissue stresses during sitting on the ACB cushion and the resulting theoretical risk for reoccurrence of PUs.

\section{METHODS}

\section{Geometry}

In order to examine the effects of muscle, fat, and skin tissue scarring in a patient with a history of buttocks PUs on the resulting mechanical stresses in these soft tissues during sitting on an ACB cushion, a set of 11 model variants were developed. Each of the model variants was developed based on a coronal cross-section of the left buttock and included the IT bone, the gluteus maximus 
skeletal muscle, the colon smooth muscle, fat tissue, skin, and the ACB cushion structure (Figure 1(a)). Ten of the model variants were incorporated with scars of different shapes and dimensions as detailed in Table 1, and one variant was used as a nonscarred $\mathrm{R}$ case.

A single coronal magnetic resonance imaging (MRI) slice acquired from a male subject $1 \mathrm{yr}$ following an SCI, who was scanned in our previous work (paraplegic subject 5 in the Linder-Ganz et al. study [34]), was used to generate the R model case. Full details of the subject and MRI system and scan protocol are available in our previous work $[6,34,42]$. We used the ScanIP module of Simpleware (Exeter, United Kingdom) [43] to segment the different tissue components from the MRI slice and then to define a uniform $4 \mathrm{~mm}$ thickness to the entire anatomical model. In 10 of the model variants, scars of different shapes and dimensions were incorporated: thin skin scar (Thin), hypertrophic skin scar, two severities of deep muscle scarring, two severities of superficial fat and skin scarring, two severities of sandwich-shaped scarring (SW I and SW II), and two severities of hourglass-shaped scarring (HG I and HG II) (Figure 1(a)). The shapes of the scars were chosen corresponding to the modeling work of Sopher et al. [21], though the specific percentage volumes occupied by scarred tissues differed slightly from their work (Table 1).

The geometrical model of the ACB cushion was based on a slice through the tops of the air cells in a preinflated configuration. Using the $+\mathrm{CAD}$ module of Simpleware [43], we converted the computer-aided design slice to a voxel array database, then defined a uniform $4 \mathrm{~mm}$ thickness to the ACB cushion slice and incorporated the ACB cushion with the anatomical model in the ScanIP module of Simpleware [43].

\section{Mechanical Properties}

Constitutive laws and mechanical properties of all tissues were adopted from the literature (Table 2). Specifically, the IT bone was assumed to be a linear-elastic isotropic material with elastic modulus of $7 \mathrm{GPa}$ and Poisson's ratio of 0.300 [22]. The muscle, fat, and skin tissues were assumed to be nearly incompressible (Poisson's ratio of 0.495), nonlinear isotropic materials with their large deformation behavior described using an uncoupled Neo-Hookean material model [44] with a strain energy density function $W$ (Equation 1):

$$
w=\frac{G_{i n s}}{2}\left(\lambda_{1}^{2}+\lambda_{2}^{2}+\lambda_{3}^{2}-3\right)+\frac{1}{2} K(\ln J)^{2},
$$

\section{(a)}
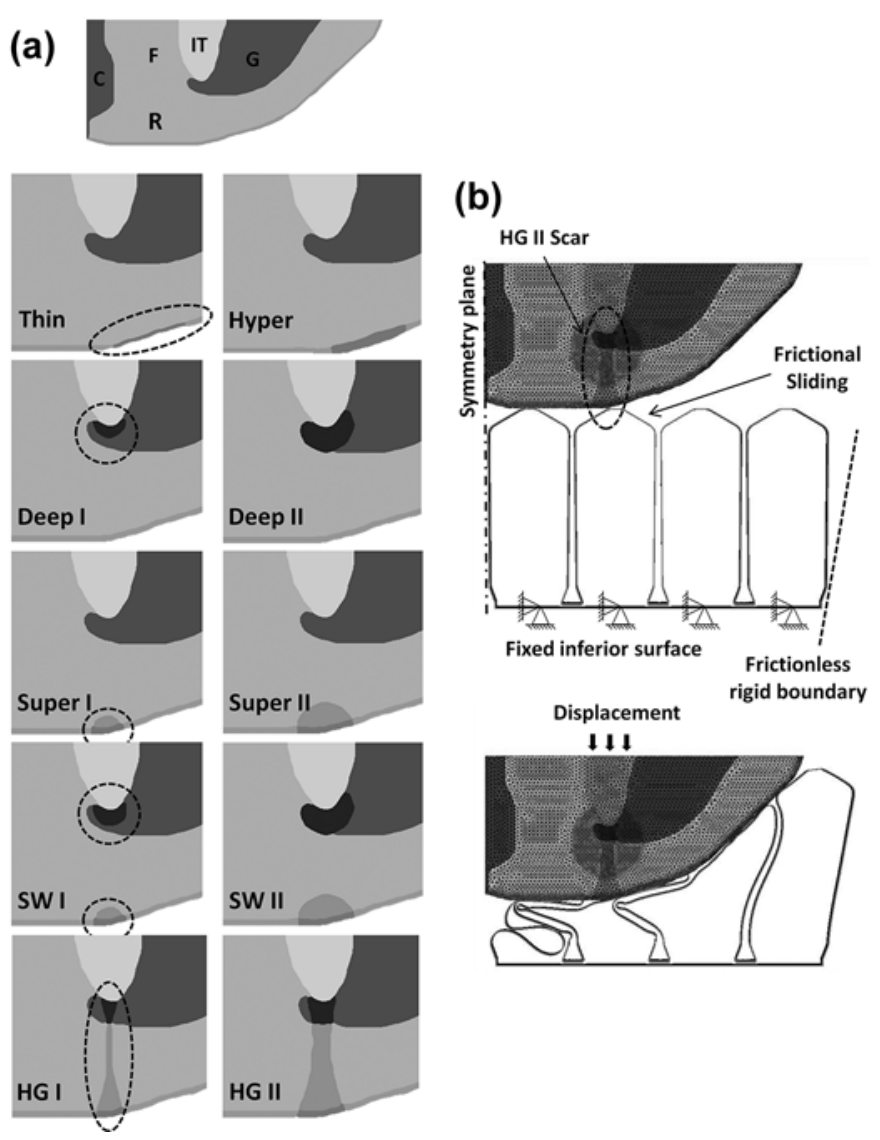

Figure 1.

Finite element computational model of left buttock of individual, $1 \mathrm{yr}$ following spinal cord injury (SCl). (a) Geometrical shapes and dimensions of two levels of severity $(I=$ mild, $I I=$ severe $)$ of each simulated scar, compared with reference ( $\mathrm{SCl}$, nonscarred) anatomy (R). Model variants with different scars are magnified for clarification. $\mathrm{C}=$ colon smooth muscle, Deep = deep muscle scarring, $F=$ fat, $G=$ gluteus muscle, $H G=$ hourglass-shaped scarring, Hyper = hypertrophic scar in skin, IT = ischial tuberosity, Super = superficial skin and fat scarring, SW = sandwich-shaped scarring, Thin = scar in skin. Scars are indicated by darker colors and dashed surrounding circles. Percentage volumes occupied by scarred soft tissues are specified in Table 1. (b) Three-dimensional tetrahedral mesh together with main boundary and loading conditions of HG II model variant while sitting down on air-cell-based cushion. Boundary and loading conditions were chosen similarly to Levy et al. [42].

where $G_{\text {ins }}$ is the instantaneous shear modulus (Table 2); $\lambda_{i}(i=1,2,3)$ are the principal stretch ratios; $K$ is the bulk modulus; and $J=\operatorname{det}(F)$, where $F$ is the deformation gradient tensor. Stiffer $G_{\text {ins }}$ was allocated to scarred muscle 
JRRD, Volume 51, Number 8, 2014

Table 1.

Percent volume occupied by scarred muscle, fat, and skin tissues for reference anatomy (R), thin skin scar (Thin), hypertrophic scar in skin (Hyper), mild and severe deep muscle scarring (Deep I, Deep II), mild and severe superficial skin and fat scarring (Super I, Super II), mild and severe sandwich-shaped scarring (SW I, SW II), and mild and severe hourglass-shaped scarring (HG I, HG II). All anatomies are shown in Figure 1(a).

\begin{tabular}{|c|c|c|c|}
\hline Anatomy & Scarred Muscle (\%) & Scarred Fat (\%) & Scarred Skin (\%) \\
\hline$\overline{\mathrm{R}}$ & 0.0 & 0.0 & 0.0 \\
\hline Thin & 0.0 & 0.0 & 9.5 \\
\hline Hyper & 0.0 & 0.0 & 19.9 \\
\hline Deep I & 2.2 & 0.0 & 0.0 \\
\hline Deep II & 7.5 & 0.0 & 0.0 \\
\hline Super I & 0.0 & 0.4 & 6.7 \\
\hline Super II & 0.0 & 1.8 & 10.6 \\
\hline SW I & 3.0 & 0.4 & 6.7 \\
\hline SW II & 7.5 & 1.8 & 10.6 \\
\hline HG I & 1.4 & 1.7 & 5.5 \\
\hline HG II & 3.4 & 4.0 & 9.1 \\
\hline
\end{tabular}

Table 2.

Mechanical properties of model components and characteristics of finite element mesh.

\begin{tabular}{|c|c|c|c|c|c|}
\hline $\begin{array}{c}\text { Modal } \\
\text { Component }\end{array}$ & $\begin{array}{c}\text { Shear Modulus } \\
\text { (kPa) }\end{array}$ & $\begin{array}{l}\text { Bulk Modulus } \\
\text { (kPa) }\end{array}$ & $\begin{array}{c}\text { Elastic Modulus } \\
\text { (kPa) }\end{array}$ & $\begin{array}{c}\text { Poisson's } \\
\text { Ratio }\end{array}$ & $\begin{array}{l}\text { Number of Mesh } \\
\text { Elements }\end{array}$ \\
\hline Skin $^{*}$ & & & - & 0.495 & \\
\hline Nonscarred & 31.900 & $3,179.370$ & & & $8,016-9,230$ \\
\hline Scarred & 300.000 & $29,900.000$ & & & $500-1,626$ \\
\hline $\mathrm{Fat}^{\dagger}$ & & & - & 0.495 & \\
\hline Nonscarred & 0.286 & 28.500 & & & $27,669-29,127$ \\
\hline Scarred & 1.373 & 136.820 & & & $326-2,404$ \\
\hline Muscle $^{\dagger}$ & & & - & 0.495 & \\
\hline Nonscarred & 7.100 & 707.600 & & & $5,782-6,956$ \\
\hline Scarred & 34.080 & $3,396.600$ & & & $496-1,496$ \\
\hline Bone & - & - & $7 \times 10^{6}$ & 0.300 & $2,125-2,246$ \\
\hline ACB Cushion & - & - & 100 & 0.300 & 245,235 \\
\hline Gaps & - & - & 0.002 & 0.100 & 150,658 \\
\hline
\end{tabular}

${ }^{*}$ Data were adopted from the literature [6,21].

${ }^{\dagger}$ Data were adopted from the literature $[21,45]$.

$\mathrm{ABC}=$ air-cell-based.

and fat tissues so that the property ratio of $G_{\text {ins }}$ of scarred over nonscarred tissue was $4.8[21,45]$. The ACB cushion was assumed to be isotropic linear-elastic with a Poisson's ratio of 0.495 and an elastic modulus of $100 \mathrm{kPa}$.
Detailed description of the experimental evaluation and computational representation of the material and structural behavior of the ACB cushion is available in our previous work [42]. 


\section{Boundary and Material Transition Conditions}

Boundary conditions were chosen to simulate the vertical descent of the weight-bearing ITs during sitting on an ACB cushion in a thin slice model. All front and back planes of the ACB cushion and buttocks were fixed in the perpendicular direction to avoid out-of-plane translations. The inferior surface of the ACB cushion was fixed for all translation and rotations, frictional sliding was defined between the skin and the cushion with the coefficient of friction set to 0.4 in all simulations, and tied interfaces were defined between all tissue components (Figure 1(b)). The medial surfaces of the colon smooth muscle, skin, and ACB cushion were fixed for lateral translations to define the symmetry conditions around the medial plane (Figure 1(b)). A frictionless boundary wall that limits the lateral inclination of the lateral air cell was placed at $10^{\circ}$ to the vertical axis, accounting for the constraining effect of the fabric cover of the cushion.

A uniform vertical displacement load of $66 \mathrm{~mm}$ was applied to the superior surface of the IT so that the final outcome distance between the outer surface of the skin and the inferior surface of the ACB cushion (clinically referred to as the clearance above the "bottom-out" distance) was $32 \mathrm{~mm}$, slightly above the $1 \mathrm{in}$. distance recommended by the Agency for Healthcare Research and Quality [46]. This loading condition was kept the same across all the model variants since the tissue stiffening associated with the scarring was limited to a relatively small volume of tissue (less than $20 \%$ of the total tissue volume), and so, this local stiffening could only have a negligible influence on the overall vertical descent of the buttocks stemming from the patient's own body weight. A retrospective analysis of the loading scheme correlated the applied displacement to a vertical reaction force of approximately $100 \mathrm{~g}$ acting on the slice for the one side of the buttocks. ${ }^{*}$ Although we did not simulate the air

\footnotetext{
*For a body weight $(\mathrm{BW})$ of $70-80 \mathrm{~kg}$, the trunk weight is coarsely $50 \%$, that is, $30-40 \mathrm{~kg}$ applied on the sitting surface of the wheelchair plus the armrests. The armrests take approximately $10 \%$ of the BW [47], so roughly $30 \mathrm{~kg}$ will be distributed over the ITs and sacrum. The buttocks-cushion contact depth of support surfaces is about $40 \mathrm{~cm}$, so there are about a hundred $4 \mathrm{~mm}$ slices that are equivalent to our MRI scan resolution in a seated buttocks. Hence, each slice should take, on average, $30 \mathrm{~kg} / 100$ slices $=300 \mathrm{~g}$, which is close to the magnitude of reaction forces ( $100 \mathrm{~g}$ per each side of the buttocks, or $200 \mathrm{~g}$ in total) that was calculated directly from our modeling.
}

flow through the deforming air cells during sitting on the ACB cushion, we did apply distributed forces over the inner surfaces of the air cells $(0.2 \mathrm{~N} / \mathrm{m}$ per cell $)$, which stabilized the numerical calculations [42]. We used a photograph of the deformed ACB cushion through a transparent phantom of the buttocks in order to verify that the simulated collapse pattern of the air cells was indeed realistic [42].

\section{Numerical Method and Outcome Measures}

Meshing the model variants was performed using the ScanIP module of Simpleware [43], with finer meshes used in specific regions: the entire skin layer and around the muscle and fat tissues interfacing the IT for both nonscarred and scarred tissues (Figure 1(b)). Each model included a total of $\sim 50,000$ four-node linear tetrahedral elements assigned to the different tissues, as well as 395,893 four-node linear tetrahedral elements assigned to the ACB cushion (Table 2). The exceptionally dense mesh of the ACB cushion was essential to ensure convergence given the large deformations of the air cells (Figure 1(b)). Using greater mesh densities for the tissues yielded negligible differences in all outcome measures in terms of numerical convergence or accuracy in all model configurations (i.e., resulted in less than $2 \%$ difference for denser meshes in test analyses).

The FE simulations were all set up using PreView of FEBio (version 1.12) (Salt Lake City, Utah), analyzed using the Pardiso linear solver of FEBio (http://febio.org) (version 1.7.1) and postprocessed using PostView of FEBio (version 1.4) [48]. The runtime of each model variant was between 8 and $26 \mathrm{~h}$ using a 64-bit Windows 8-based workstation with $2 \times$ Intel Xeon E5-2620 $2.00 \mathrm{GHz}$ CPU and $32 \mathrm{~GB}$ of RAM (Microsoft; Redmond, Washington).

We compared the peak effective $\left(\sigma_{\mathrm{e}}\right)$, compressive $\left(\sigma_{\mathrm{c}}\right)$, tensile $\left(\sigma_{t}\right)$, and shear $\left(\sigma_{\mathrm{s}}\right)$ Cauchy stresses, with the effective stress defined as Equation 2 [44]:

$$
\sigma_{e}=\sqrt{\sigma_{c}^{2}}+\sigma_{t}^{2}-\sigma_{c} \times \sigma_{t}+3 \sigma_{s}^{2}
$$

for muscle, fat, and skin tissues, between all the model variants. The tissue stress data were pooled for nonscarred and scarred tissues together, per each tissue type and, separately, from each model variant as follows: (1) For fat tissue: stress data were collected only from the area below the imaginary horizontal line passing through the 
point of intersection between the fat, muscle, and bone regions; (2) For skin tissue: data were collected from all the skin elements (including those of the scars) but excluding elements that were in close proximity to the midline (up to a $10 \mathrm{~mm}$ distance); and (3) For muscle tissue: data were collected from all the elements representing the gluteus maximus skeletal muscle. We normalized all stress data with respect to the $\mathrm{R}$ case.

\section{RESULTS}

An example of a comparison of the effective stresses that develop in nonscarred and scarred muscle, fat, and skin tissues between the R, Thin, SW II (severe sandwich), and HG II (severe hourglass) model variants is shown in Figure 2. Overall, stresses were concentrated in muscle and fat tissues in the vicinity of the tip of the IT, as well as in the portion of the skin that was in contact with the ACB cushion. Elevated effective stresses could also be detected in the scarred areas of the muscles, fat, and skin tissues, particularly in the SW II and HG II cases (Figure 2(c)-(d)). Peak effective, compressive, tensile, and shear stress values for the $\mathrm{R}$ case are listed in Table 3.

When seated on the ACB cushion, soft tissue scarring interestingly induced, in general, lower peak stress values in the soft tissues of the buttocks with respect to the stress levels in the (nonscarred) R configuration (Figures 3-5). Specifically, gluteus muscle peak effective and shear stresses decreased by 10 to 45 percent in 9 of the 10 scars simulated herein (Figure 3). An exception was the HG I case, where peak effective and shear muscle stresses increased mildly $(12 \%-14 \%)$. This was most likely due to the triangular shape of the muscle scar region (Figure 1(a)), which aligns with the (vertical) load bearing direction (and with the gravity vector), and therefore causes stresses to concentrate downwards from the IT tip.

Likewise, peak effective and shear stresses in fat tissue of a scarred buttocks generally decreased on the ACB cushion with respect to the $\mathrm{R}$ case by 40 to 65 percent in all the simulated scar types apart from the hourglassshaped scars (HG I, HG II cases). The two aforementioned scar severities were associated with a milder $(10 \%-15 \%)$ decrease in peak effective and shear stresses (Figure 4), which could again be attributed to the alignment of these scars with the loading vector (Figure 1(a)).
The exceptions were the SW II and HG I cases, where peak compressive stresses increased by 25 and 30 percent, respectively, corresponding to the relatively high volume fraction occupied by scarred fat that then adds to the effect of the geometrical directionality of these scars.

Peak effective and shear stresses in the skin decreased by up to 40 percent in all of the simulated scar cases. However, peak compressive and tensile stresses in the Thin case increased by 30 and 50 percent, respectively. In addition, the HG II case resulted in an increase of 25 percent in skin peak tensile stress, which in this case can be attributed to the large skin volume that is taken by the scar.

To verify that the ACB cushion is generally better at protecting patients with a history of severe PUs manifested by large, possibly deep tissue scarring in their buttocks, as this simulation data suggest, the analyses were repeated for the most severe scar cases on a flat foam cushion instead of an ACB cushion. We considered a flat foam cushion with elastic modulus of $25 \mathrm{kPa}$ (associated with an apparent foam density of $\sim 0.01 \mathrm{~g} / \mathrm{cm}^{3}$ ), similarly to foam cushions that were simulated in our previous work [42]. For example, we found that on a flat foam cushion, the HG II scar type caused an average increase of 155 and 70 percent in peak fat and muscle stresses, respectively, when compared against the $\mathrm{R}$ case on the same flat foam cushion.

\section{DISCUSSION}

The importance of using a soft and thick-enough cushion on the wheelchair for PU prevention, especially in the SCI patient population, is often highlighted in the literature, but typically just in general terms and without referring to subgroups with specific potential risk factors. In earlier work, we have demonstrated how FE modeling could aid in analyzing the relative contributions of potential risk factors that affect the biomechanical performances of the seated buttocks, such as an abnormal body mass index, muscle atrophy, bone shape adaptation to disuse, intramuscular fat infiltration, and tissue scarring [20-21,33]. However, all the aforementioned modeling studies considered sitting on simple, flat foam cushions. On the other hand, we were recently able to simulate the 


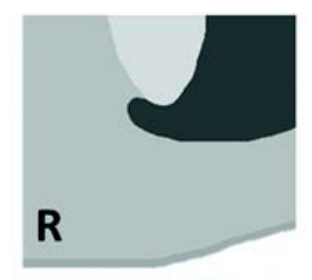

(a)

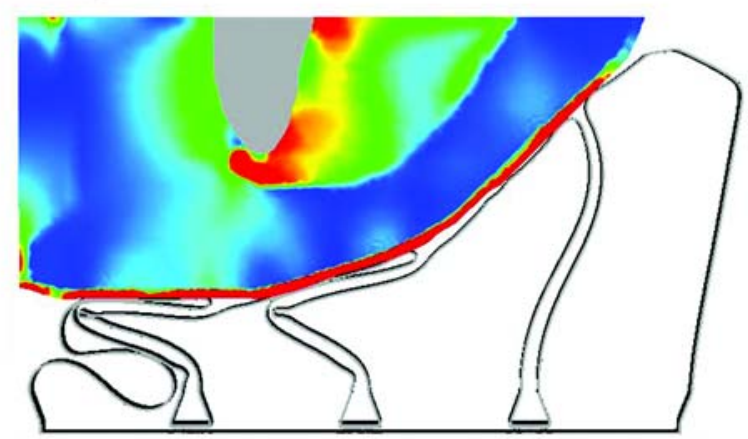

(b)
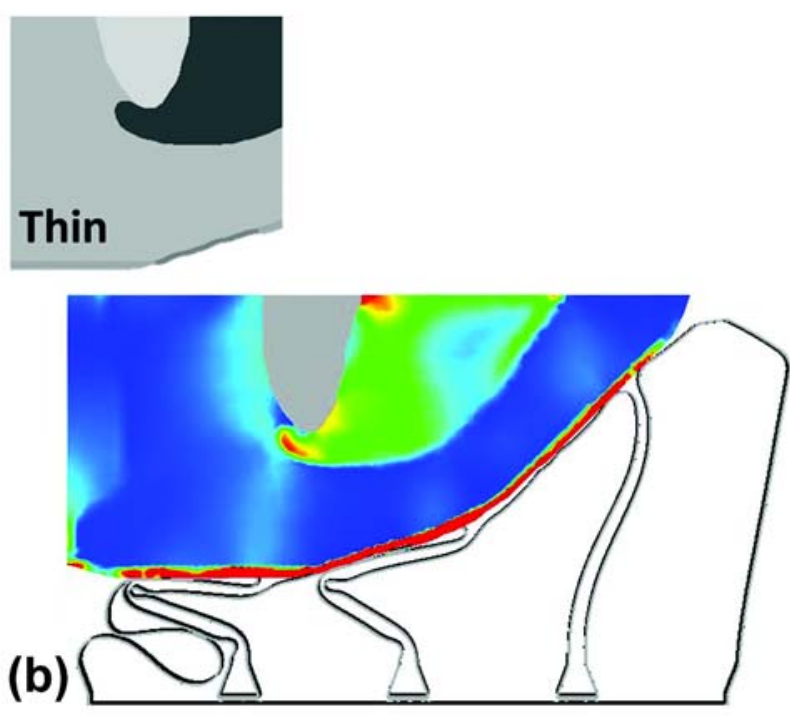

0.12

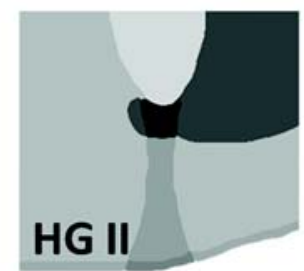

0.09
0.06

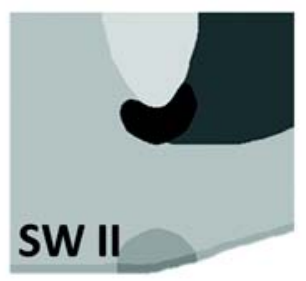

HG I

[Pa]

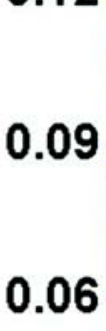

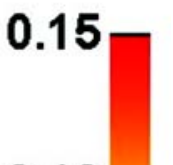

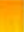

(c)
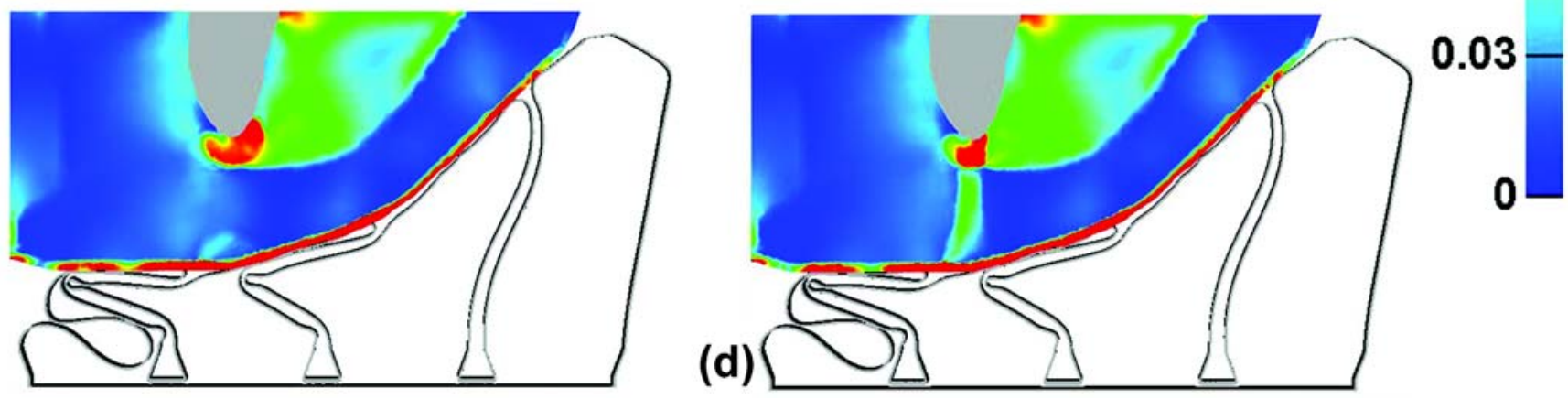

Figure 2.

Comparison of effective stress distributions in soft tissues of left buttock when seated on air-cell-based cushion between (a) reference (R) anatomy, (b) thin skin scar (Thin), (c) severe sandwich-shaped scar (SW II), and (d) severe hourglass-shaped scar (HG II).

Table 3.

Peak stresses in soft tissues of buttocks when seated on air-cell-based cushion for reference (nonscarred) model variant.

\begin{tabular}{lcccc} 
Tissue & $\begin{array}{c}\text { Peak } \\
\text { Effective Stress (Pa) }\end{array}$ & $\begin{array}{c}\text { Peak } \\
\text { Compressive Stress (Pa) }\end{array}$ & $\begin{array}{c}\text { Peak } \\
\text { Tensile Stress (Pa) }\end{array}$ & $\begin{array}{c}\text { Peak } \\
\text { Shear Stress (Pa) }\end{array}$ \\
\hline Tluteus Muscle & 0.36 & 2.95 & 1.72 & 0.21 \\
Tkin & 0.07 & 0.78 & 0.64 & 0.06 \\
\hline
\end{tabular}



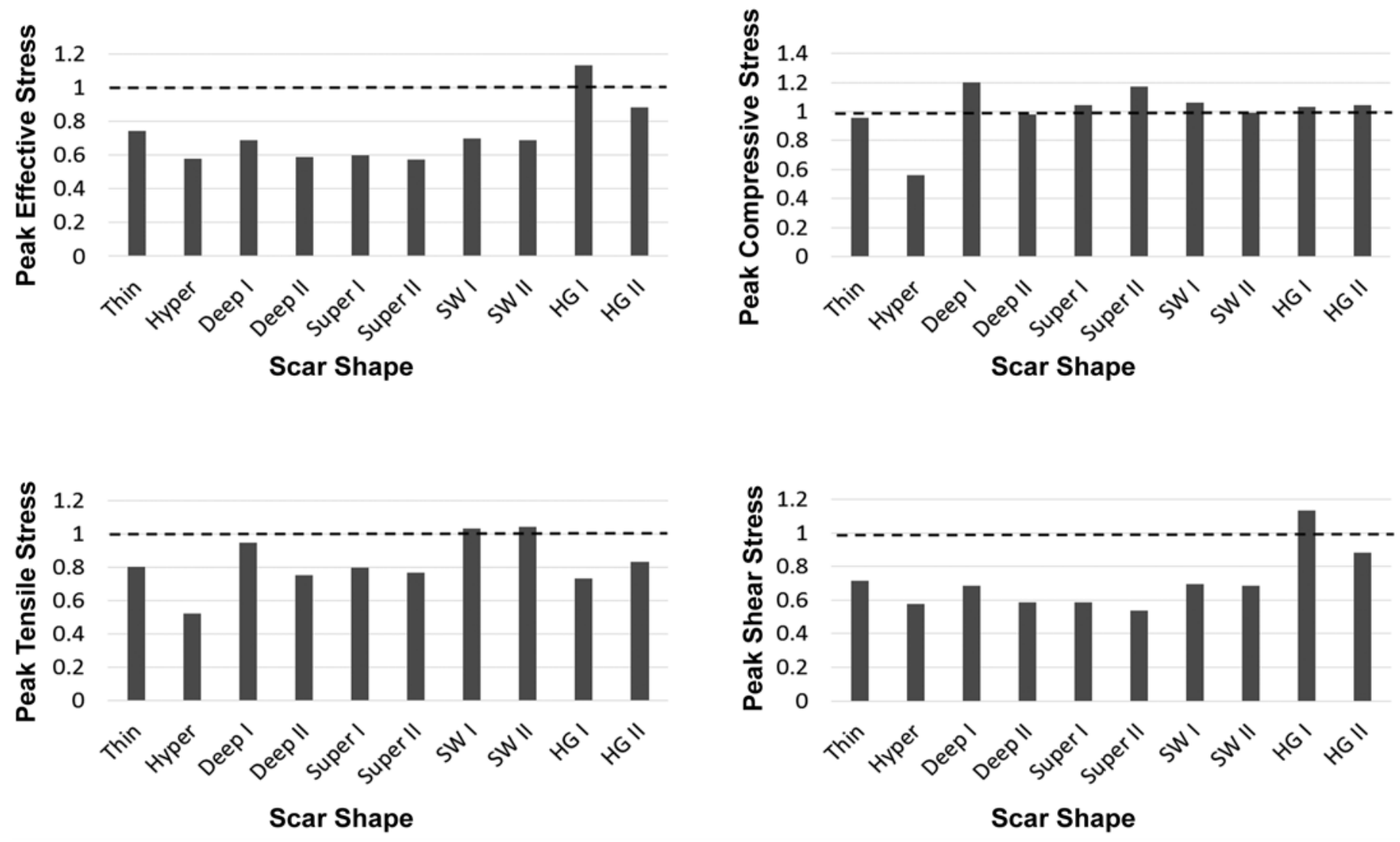

Figure 3.

Peak stresses in gluteus muscle tissues when seated on air-cell-based cushion for each simulated scar shape and severity. Values are normalized with respect to reference (nonscarred) model variant for which stress values are listed in Table $\mathbf{3}$. I = mild, $\mathrm{II}=$ severe, Deep = deep muscle scarring, HG = hourglass-shaped scarring, Hyper = hypertrophic skin scar, Super = superficial fat and skin scarring, SW = sandwich-shaped scarring, Thin $=$ thin skin scar.

physical behavior and biomechanical efficacy of a substantially more complex cushion structure - the ACB cushion [42]. A natural step forward would therefore be to join the two advancements together and simulate how an ACB cushion would perform with patients who are at a potentially increased risk - ones who have previously experienced PUs that healed but left moderate to serious scars [49]. That is, indeed, the focus of the present article.

Specifically, in this study, we used 11 FE MRI-based model variants of the left buttock of an individual after an SCI in order to evaluate the biomechanical performances of an ACB cushion when interacting with buttocks structures that contain different types and severities of soft tissue scarring. The work largely builds on the Sopher et al. article, which examined the biomechanical influence of similar soft tissue scarring scenarios but when seated on simple, flat foam cushions [21]. The Sopher et al. article reported an overall increase in muscle stresses with the presence and severity of (deep) scarring and therefore indicated an elevated risk for a new sitting-acquired DTI in patients with a history of PUs who sit on flat foam cushions. Likewise, the later article by Levy et al., which focused on skin scars in the buttocks of a patient sitting on flat foams, pointed to the trend of scars being an inclusion that increases adjacent tissue loading on the foam cushion [33]. Contrarily to that, here we found decreased peak muscle stresses adjacent to the scar region in all the simulated scar cases excluding the HG I case (Figures 2-3). This means that, based on the present computational simulations, the ACB cushion is likely to better protect patients with deep scars against DTIs than flat foams, presumably through the 


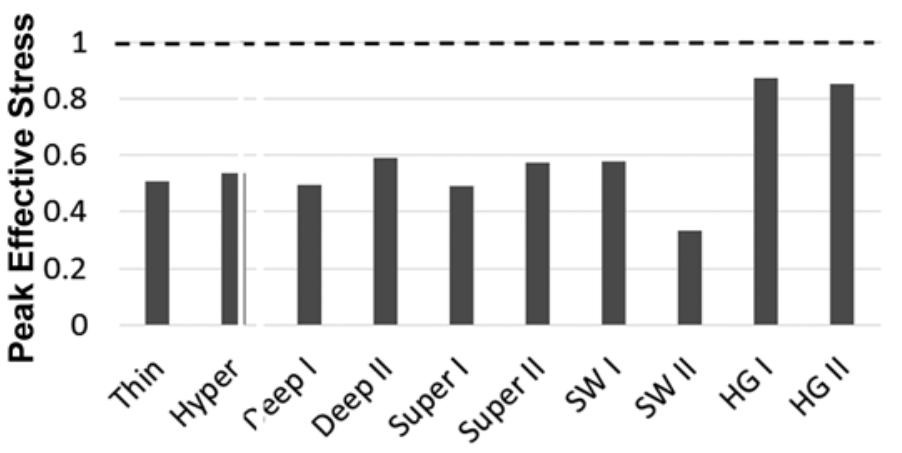

Scar Shape

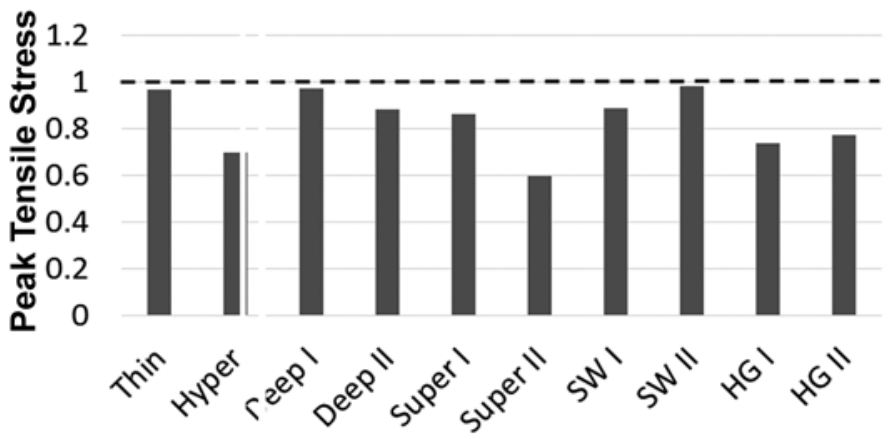

Scar Shape

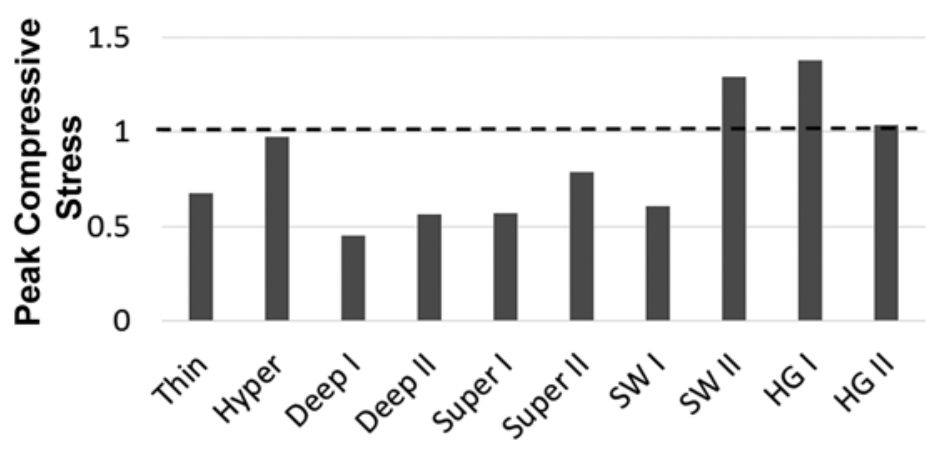

Scar Shape

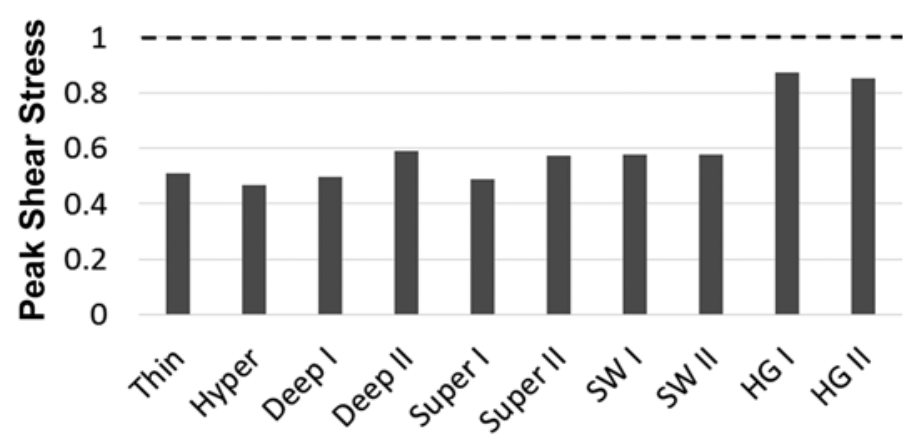

Scar Shape

Figure 4.

Peak stresses in fat tissues when seated on air-cell-based cushion for each simulated scar shape and severity. Values are normalized with respect to reference (nonscarred) model variant for which stress values are listed in Table 3. I= mild, $I I=$ severe, Deep = deep muscle scarring, HG = hourglass-shaped scarring, Hyper = hypertrophic skin scar, Super = superficial fat and skin scarring, SW = sandwich-shaped scarring, Thin = thin skin scar.

improved immersion and envelopment facilitated by the ACB cushion, unless the scar is so large that it occupies most of the volume of the muscle tissue under the IT. This fundamentally improved (though theoretical) efficacy of the ACB cushion with respect to flat foams, when it comes to managing patients with existing muscle tissue scars, may be particularly useful in preventing reoccurrence of PUs and specifically DTIs.

Despite the observed differences in the resulting trends of tissue stresses between the ACB cushion and flat foam cushions, as explained previously, the increased risk imposed by hourglass-shaped scars, on any cushion, is evident and consistent in our present study and previous work [21]. Unlike the other simulated scars, the cases of hourglass-shaped scars (HG I, HG II) yielded considerable increases in compression stresses in fat and tensile stresses in skin, which can potentially compromise the viability of tissues around the scarred regions. This again points to the importance of preventing the first occurrence of a $\mathrm{PU}$, and if occurring, then minimizing the spread of tissue damage given that large, penetrating scars will create a mechanical lesion that will increase the risk of a recurrent injury for the rest of the patient's life.

The most important result from the present study was that an ACB cushion generally tends to lower peak stresses in muscle, fat, and skin tissues when scars of different shapes and dimensions exist. However, modeling always involves limitations originating from the inherent assumptions and omissions. First, biological effects such as blood vessel dynamics, inflammation, and ischemic damage from sustained tissue deformations are not considered in our modeling. The modeling limitations related to 


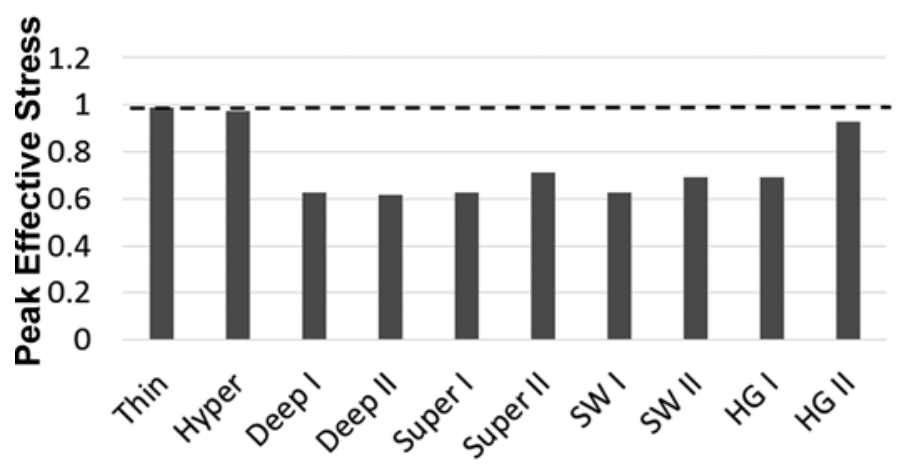

Scar Shape

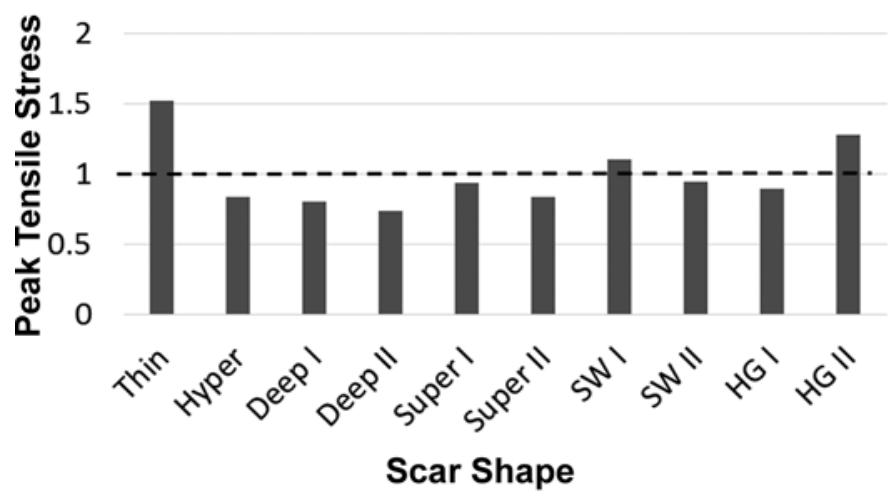

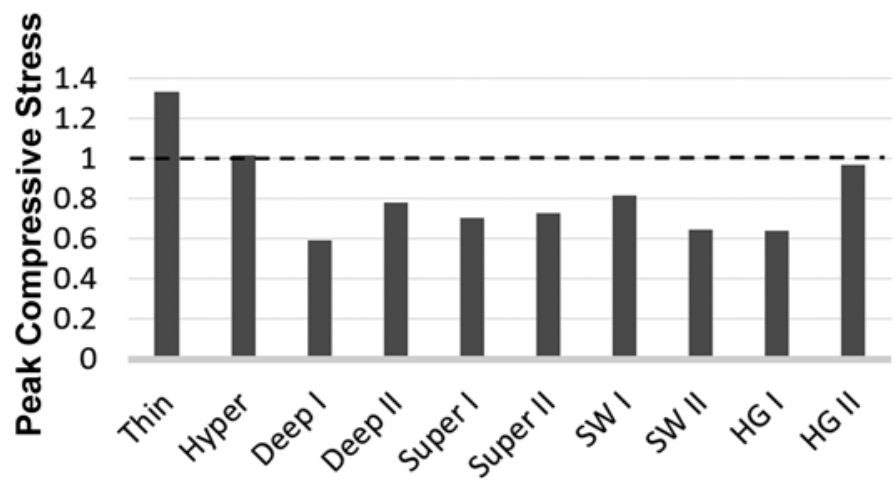

Scar Shape

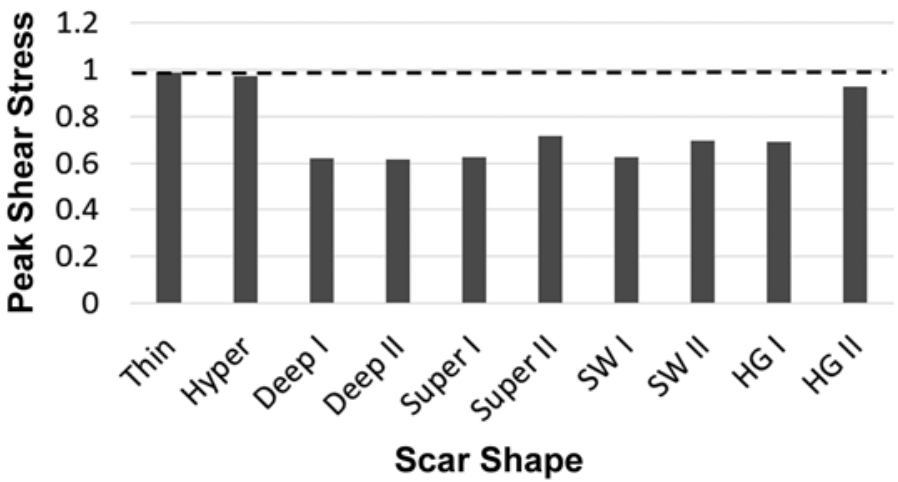

Figure 5.

Peak stresses in skin tissues when seated on air-cell-based cushion for each simulated scar shape and severity. Values are normalized with respect to reference (nonscarred) model variant for which stress values are listed in Table 3. I = mild, II = severe, Deep = deep muscle scarring, HG = hourglass-shaped scarring, Hyper = hypertrophic skin scar, Super = superficial fat and skin scarring, SW = sandwich-shaped scarring, Thin = thin skin scar.

acquiring the buttocks geometry from an MRI slice were discussed in detail in our previous work [33]. In addition to those, the mechanical properties of tissues are mostly adopted from animal tissue data, and properties of scar tissues are still poorly studied. In this regard, paucity of experimental data characterizing the properties of scarred fat compelled us to assume the same proportion of tissue stiffening as in scarred muscles [21]. Furthermore, reducing the real-world physical conditions to a buttocks cushion slice model imposes additional limitations, as threedimensional (3D) buttocks-cushion interactions are not considered, particularly with respect to out-of-plane forces and shear effects.

In this context, it should be noted that Equation 2 may give slightly greater weighting to the in-plane shear stresses in this semi-3D (slice) model of the buttocks. Though the effective stresses calculated by means of Equation 2 also account for out-of-plane stress compo- nents (i.e., along the $4 \mathrm{~mm}$ thickness/depth of the MRI slice), these out-of-plane stresses are substantially lower than the in-plane stresses in our modeling. In the anatomical planes of the model variants, shear stresses in subdermal tissues are critically important given that the differences in stiffnesses of tissue types, particularly between scarred tissues and adjacent, nonscarred tissues cause the tissue components to move or "slide" against each other. Accordingly, though Equation 2 may mildly amplify this effect (as a result of its formulation), from a pathophysiological perspective this is the phenomenon that is directly being studied here.

\section{CONCLUSIONS}

In closure, the improved immersion and envelopment facilitated by the ACB cushion allows for improved 
stress distributions in the soft tissues of the buttocks [42], which here also manifests as lower peak stress values in the scarred, stiffer tissue areas. Nevertheless, before any solid medical recommendations can be made, additional epidemiological or clinical evidence needs to be obtained in order to establish a connection between the likelihood of reoccurrence of PUs (DTIs in particular) and the cushion type being used. Moreover, assuming that ambient temperatures may affect the mechanical properties of the cushion in the short- and long-terms and that microclimate factors such as humidity and moisture change the frictional behavior, stiffness, and strength of skin, a focused modeling work addressing these issues should be a next step toward understanding the buttocks-support interactions relevant to PUs.

\section{ACKNOWLEDGMENTS}

\section{Author Contributions:}

Study concept and design: A. Levy, K. Kopplin, A. Gefen.

Acquisition of data: A. Levy.

Analysis and interpretation of data: A. Levy, K. Kopplin, A. Gefen.

Drafting of manuscript: A. Levy.

Critical revision of manuscript for important intellectual content:

K. Kopplin, A. Gefen.

Obtained funding: A. Gefen.

Study supervision: A. Gefen.

Financial Disclosures: The senior author (A.G.) is the Chair of ROHO Inc's Scientific Advisory Board. This support is however irrelevant to the data that were presented and the conclusions that were made here.

Funding/Support: This material was based on work supported by a grant from ROHO Inc (www.roho.com) aimed at developing computational models for evaluating the effects of cushioning materials and designs on buttocks tissues during weight bearing.

\section{REFERENCES}

1. European Pressure Ulcer Advisory Panel (EPUAP) and National Pressure Ulcer Advisory Panel. (NPUAP) International guidelines; 2009. Available from: http://www.epuap.org/ guidelines/

2. Gefen A. How do microclimate factors affect the risk for superficial pressure ulcers: A mathematical modeling study. J Tissue Viability. 2011;20(3):81-88. [PMID:21115351] http://dx.doi.org/10.1016/j.jtv.2010.10.002

3. Gefen A. The biomechanics of sitting-acquired pressure ulcers in patients with spinal cord injury or lesions. Int Wound J. 2007;4(3):222-31. [PMID:17924879] http://dx.doi.org/10.1111/j.1742-481X.2007.00330.x
4. Johnson RL, Gerhart KA, McCray J, Menconi JC, Whiteneck GG. Secondary conditions following spinal cord injury in a population-based sample. Spinal Cord. 1998; 36(1):45-50. [PMID:9471138] http://dx.doi.org/10.1038/sj.sc.3100494

5. Black JM; National Pressure Ulcer Advisory Panel. Moving toward consensus on deep tissue injury and pressure ulcer staging. Adv Skin Wound Care. 2005;18(8):415-16, 418, 420-21. [PMID:16217153] http://dx.doi.org/10.1097/00129334-200510000-00008

6. Linder-Ganz E, Shabshin N, Itzchak Y, Gefen A. Assessment of mechanical conditions in sub-dermal tissues during sitting: A combined experimental-MRI and finite element approach. J Biomech. 2007;40(7):1443-54.

[PMID:16920122]

http://dx.doi.org/10.1016/j.jbiomech.2006.06.020

7. Garber SL, Rintala DH, Hart KA, Fuhrer MJ. Pressure ulcer risk in spinal cord injury: Predictors of ulcer status over 3 years. Arch Phys Med Rehabil. 2000;81(4):465-71. [PMID:10768537] http://dx.doi.org/10.1053/mr.2000.3889

8. Raghavan P, Raza WA, Ahmed YS, Chamberlain MA. Prevalence of pressure sores in a community sample of spinal injury patients. Clin Rehabil. 2003;17(8):879-84.

[PMID:14682560] http://dx.doi.org/10.1191/0269215503cr692oa

9. Cardenas DD, Hoffman JM, Kirshblum S, McKinley W. Etiology and incidence of rehospitalization after traumatic spinal cord injury: A multicenter analysis. Arch Phys Med Rehabil. 2004;85(11):1757-63. [PMID:15520970] http://dx.doi.org/10.1016/j.apmr.2004.03.016

10. Allman RM, Goode PS, Burst N, Bartolucci AA, Thomas DR. Pressure ulcers, hospital complications, and disease severity: Impact on hospital costs and length of stay. Adv Wound Care. 1999;12(1):22-30. [PMID:10326353]

11. Hopkins A, Dealey C, Bale S, Defloor T, Worboys F. Patient stories of living with a pressure ulcer. J Adv Nurs. 2006;56(4):345-53. [PMID:17042814] http://dx.doi.org/10.1111/j.1365-2648.2006.04007.x

12. Chan BC, Nanwa N, Mittmann N, Bryant D, Coyte PC, Houghton PE. The average cost of pressure ulcer management in a community dwelling spinal cord injury population. Int Wound J. 2013;10(4):431-40. [PMID:22715990] http://dx.doi.org/10.1111/j.1742-481X.2012.01002.x

13. Duncan KD. Preventing pressure ulcers: The goal is zero. Jt Comm J Qual Patient Saf. 2007;33(10):605-10. [PMID: 18030862]

14. Agam L, Gefen A. Pressure ulcers and deep tissue injury: A bioengineering perspective. J Wound Care. 2007;16(8): 336-42. [PMID:17927080] http://dx.doi.org/10.12968/jowc.2007.16.8.27854 
15. Demol J, Deun DV, Haex B, Oosterwyck HV, Sloten JV. Modelling the effect of repositioning on the evolution of skeletal muscle damage in deep tissue injury. Biomech Model Mechanobiol. 2013;12(2):267-79. [PMID:22576902] http://dx.doi.org/10.1007/s10237-012-0397-4

16. Slomka N, Gefen A. Relationship between strain levels and permeability of the plasma membrane in statically stretched myoblasts. Ann Biomed Eng. 2012;40(3):606-18. [PMID:21979169] http://dx.doi.org/10.1007/s10439-011-0423-1

17. Gefen A, van Nierop B, Bader DL, Oomens CW. Straintime cell-death threshold for skeletal muscle in a tissueengineered model system for deep tissue injury. J Biomech. 2008;41(9):2003-12. [PMID:18501912] http://dx.doi.org/10.1016/j.jbiomech.2008.03.039

18. Loerakker S, Manders E, Strijkers GJ, Nicolay K, Baaijens FP, Bader DL, Oomens CW. The effects of deformation, ischemia, and reperfusion on the development of muscle damage during prolonged loading. J Appl Physiol. 2011; 111(4):1168-77. [PMID:21757578] http://dx.doi.org/10.1152/japplphysiol.00389.2011

19. Mak AF, Yu Y, Kwan LP, Sun L, Tam EW. Deformation and reperfusion damages and their accumulation in subcutaneous tissues during loading and unloading: A theoretical modeling of deep tissue injuries. J Theor Biol. 2011;289: 65-73. [PMID:21884707] http://dx.doi.org/10.1016/j.jtbi.2011.08.022

20. Sopher R, Nixon J, Gorecki C, Gefen A. Exposure to internal muscle tissue loads under the ischial tuberosities during sitting is elevated at abnormally high or low body mass indices. J Biomech. 2010;43(2):280-86. [PMID:19762029] http://dx.doi.org/10.1016/j.jbiomech.2009.08.021

21. Sopher R, Nixon J, Gorecki C, Gefen A. Effects of intramuscular fat infiltration, scarring, and spasticity on the risk for sitting-acquired deep tissue injury in spinal cord injury patients. J Biomech Eng. 2011;133(2):021011.

[PMID:21280883]

http://dx.doi.org/10.1115/1.4003325

22. Elsner JJ, Gefen A. Is obesity a risk factor for deep tissue injury in patients with spinal cord injury? J Biomech. 2008;41(16):3322-31. [PMID:19026415] http://dx.doi.org/10.1016/j.jbiomech.2008.09.036

23. Gefen A. Tissue changes in patients following spinal cord injury and implications for wheelchair cushions and tissue loading: A literature review. Ostomy Wound Manage. 2014; 60(2):34-45. [PMID:24515983]

24. Castro MJ, Apple DF Jr, Staron RS, Campos GE, Dudley GA. Influence of complete spinal cord injury on skeletal muscle within 6 mo of injury. J Appl Physiol (1985). 1999;86(1):350-58. [PMID:9887150]
25. de Bruin ED, Herzog R, Rozendal RH, Michel D, Stüssi E. Estimation of geometric properties of cortical bone in spinal cord injury. Arch Phys Med Rehabil. 2000;81(2):150-56.

[PMID:10668767]

http://dx.doi.org/10.1016/S0003-9993(00)90133-3

26. Giangregorio L, McCartney N. Bone loss and muscle atrophy in spinal cord injury: Epidemiology, fracture prediction, and rehabilitation strategies. J Spinal Cord Med. 2006;29(5):489-500. [PMID:17274487]

27. Rittweger J, Gerrits K, Altenburg T, Reeves N, Maganaris $\mathrm{CN}$, de Haan A. Bone adaptation to altered loading after spinal cord injury: A study of bone and muscle strength. J Musculoskelet Neuronal Interact. 2006;6(3):269-76. [PMID:17142949]

28. Gélis A, Dupeyron A, Legros P, Benaïm C, Pelissier J, Fattal C. Pressure ulcer risk factors in persons with spinal cord injury part 2: The chronic stage. Spinal Cord. 2009;47(9): 651-61. [PMID:19350047] http://dx.doi.org/10.1038/sc.2009.32

29. Provenzano PP, Martinez DA, Grindeland RE, Dwyer KW, Turner J, Vailas AC, Vanderby R Jr. Hindlimb unloading alters ligament healing. J Appl Physiol. 2003;94(1):314-24. [PMID:12391134]

30. Bates-Jensen BM, Guihan M, Garber SL, Chin AS, Burns SP. Characteristics of recurrent pressure ulcers in veterans with spinal cord injury. J Spinal Cord Med. 2009;32(1):3442. [PMID:19264047]

31. Beeckman D, Vanderwee K. Skin protection wheelchair cushions for older nursing home residents reduce 6-month incidence of ischial tuberosity pressure ulcers compared with segmented foam cushions. Evid Based Nurs. 2011;14(3):79-80. [PMID:21646383] http://dx.doi.org/10.1136/ebn1167

32. Bader D. Journal of Tissue Viability. Editorial. J Tissue Viability. 2013;22(2):23-24. [PMID:23602508]

http://dx.doi.org/10.1016/j.jtv.2013.03.002

33. Levy A, Kopplin K, Gefen A. Simulations of skin and subcutaneous tissue loading in the buttocks while regaining weight-bearing after a push-up in wheelchair users. J Mech Behav Biomed Mater. 2013;28:436-47. [PMID:23706990] http://dx.doi.org/10.1016/j.jmbbm.2013.04.015

34. Linder-Ganz E, Shabshin N, Itzchak Y, Yizhar Z, Siev-Ner I, Gefen A. Strains and stresses in sub-dermal tissues of the buttocks are greater in paraplegics than in healthy during sitting. J Biomech. 2008;41(3):567-80. [PMID:18054024] http://dx.doi.org/10.1016/j.jbiomech.2007.10.011

35. Linder-Ganz E, Gefen A. Stress analyses coupled with damage laws to determine biomechanical risk factors for deep tissue injury during sitting. J Biomech Eng. 2009; 131(1):011003-13. [PMID:19045919] http://dx.doi.org/10.1115/1.3005195 
36. Oomens CW, Bressers OF, Bosboom EM, Bouten CV, Blader DL. Can loaded interface characteristics influence strain distributions in muscle adjacent to bony prominences? Comput Methods Biomech Biomed Engin. 2003; 6(3):171-80. [PMID:12888429] http://dx.doi.org/10.1080/1025584031000121034

37. Ragan R, Kernozek TW, Bidar M, Matheson JW. Seatinterface pressures on various thicknesses of foam wheelchair cushions: A finite modeling approach. Arch Phys Med Rehabil. 2002;83(6):872-75. [PMID:12048671] http://dx.doi.org/10.1053/apmr.2002.32677

38. Shabshin N, Zoizner G, Herman A, Ougortsin V, Gefen A. Use of weight-bearing MRI for evaluating wheelchair cushions based on internal soft-tissue deformations under ischial tuberosities. J Rehabil Res Dev. 2010;47(1):31-42. [PMID:20437325] http://dx.doi.org/10.1682/JRRD.2009.07.0105

39. Todd BA, Thacker JG. Three-dimensional computer model of the human buttocks, in vivo. J Rehabil Res Dev. 1994;31(2):111-19. [PMID:7965867]

40. Verver MM, van Hoof J, Oomens CW, Wismans JS, Baaijens FP. A finite element model of the human buttocks for prediction of seat pressure distributions. Comput Methods Biomech Biomed Engin. 2004;7(4):193-203. [PMID:15512763] http://dx.doi.org/10.1080/10255840410001727832

41. Li S, Zhang Z, Wang J. A new custom-contoured cushion system based on Finite Element modeling prediction. J Mech Med Biol. 2013;13(04):135-51. http://dx.doi.org/10.1142/S0219519413500516

42. Levy A, Kopplin K, Gefen A. An air-cell-based cushion for pressure ulcer protection remarkably reduces tissue stresses in the seated buttocks with respect to foams: Finite element studies. J Tissue Viability. 2014;23(1):13-23.

[PMID:24405723] http://dx.doi.org/10.1016/j.jtv.2013.12.005

43. Simpleware. ScanIP, + FE, + NURBS and + CAD reference guide ver. 5.1 [Internet]. Exeter (United Kingdom): Simpleware Ltd; 2012. Available from: http://www.simpleware.com/software/
44. FEBio. Finite element for biomechanics, theory manual ver. 1.5 [Internet]. Salt Lake City (UT): University of Utah; 2012. Available from: http://febio.org

45. Gupta KB, Ratcliffe MB, Fallert MA, Edmunds LH Jr, Bogen DK. Changes in passive mechanical stiffness of myocardial tissue with aneurysm formation. Circulation. 1994;89(5):2315-26. [PMID:8181158] http://dx.doi.org/10.1161/01.CIR.89.5.2315

46. National Guideline Clearinghouse. Guideline synthesis: Prevention of pressure ulcers. Rockville (MD): Agency for Healthcare Research and Quality; 2006.

47. Gilsdorf P, Patterson R, Fisher S, Appel N. Sitting forces and wheelchair mechanics. J Rehabil Res Dev. 1990;27(3): 239-46. [PMID:2401955] http://dx.doi.org/10.1682/JRRD.1990.07.0239

48. Maas SA, Ellis BJ, Ateshian GA, Weiss JA. FEBio: Finite elements for biomechanics. J Biomech Eng. 2012;134(1): 011005. [PMID:22482660] http://dx.doi.org/10.1115/1.4005694

49. Allman RM, Goode PS, Patrick MM, Burst N, Bartolucci AA. Pressure ulcer risk factors among hospitalized patients with activity limitation. JAMA. 1995;273(11):865-70. [PMID:7869557] http://dx.doi.org/10.1001/jama.1995.03520350047027

Submitted for publication February 15, 2014. Accepted in revised form July 3, 2014.

This article and any supplementary material should be cited as follows:

Levy A, Kopplin K, Gefen A. Computer simulations of efficacy of air-cell-based cushions in protecting against reoccurrence of pressure ulcers. J Rehabil Res Dev. 2014;51(8):1297-1310. http://dx.doi.org/10.1682/JRRD.2014.02.0048

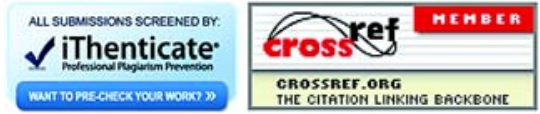


